\title{
A TEMPORAL VARIATION OF LEWIS-KOSTIAKOV COEFFICIENTS EQUAL IN DIFFERENT FURROW IRRIGATION MANAGEMENTS IN SUGAR BEET (BETA VULGARIS L.) CULTIVATION IN KARAJ, IRAN
}

\author{
MANSURI, M. ${ }^{1}-$ BABAZADEH, H. ${ }^{1 *}-$ EMDAD, M. R. ${ }^{2}-$ TALEGHANI, D. $^{3}$ \\ ${ }^{I}$ Department of Water Science and Engineering, Science and Research Branch, Islamic Azad \\ University, Tehran, Iran \\ ${ }^{2}$ Department of Irrigation and Soil Physics, Soil and Water Research Institute, Agricultural \\ Research, Education and Extension Organization (AREEO), Karaj, Iran \\ ${ }^{3}$ Sugar Beet Seed Institute, Agricultural Research, Education and Extension Organization \\ (AREEO), Karaj, Iran \\ *Corresponding author \\ e-mail:h_babazadeh@hotmail.com; phone:+98-912-699-0105
}

(Received $14^{\text {th }}$ Jan 2018; accepted $3^{\text {rd }}$ Apr 2018)

\begin{abstract}
Surface irrigation, including border, basin and furrow irrigation is used more than pressurized irrigation due to the low cost and energy requirement. However, more precise selection of design parameters for efficient design of surface irrigation is required for higher irrigation efficiency, and the accurate prediction of the infiltration rate is of prime importance. Field data sets for irrigation events during sugar beet growing season were collected for characterizing infiltration properties in alternate, fixed and conventional furrow irrigation (AFI, FFI and CFI, respectively), carried out on a clay loam soil in Karaj, Iran. The treatment was applied in two consecutive years (2013 and 2014) as randomized complete block design with three replications. Therefore, this research was conducted to determine the parameters of Lewis-Kostiakov infiltration model based on the data obtained in advancing stage and twopointed method. Less runoff losses and large infiltration rate observed in AFI as compared to CFI due to increased lateral water movement to non-irrigation furrow. Having different infiltration characteristics in AFI, design will be different from CFI in the same field. Results indicated that the final soil infiltration was $1.6 * 10^{-4} \mathrm{~m}^{3} / \mathrm{m} / \mathrm{min}$ at the beginning of the growing season and decreased in CFI, FFI and AFI management system by 44,38 and $30 \%$ respectively, at the end of growing season. The amount of ' $\mathrm{a}$ ' coefficient variations in Kostiakov-Lewis model, showed a decreasing trend during the growing season, but the ' $k$ ' coefficient had an incremental trend in CFI, FFI and AFI irrigation management system. AFI had greater infiltration rate than FFI, the steady infiltration rate in AFI and FFI was higher than CFI. Consequently, alternate furrow irrigation management with reduced drainage achieved maximum water use efficiency (WUE).
\end{abstract}

Keywords: furrow irrigation, final infiltration, drainage, surface irrigation, irrigation management

\section{Introduction}

Water sources suitable for utilization are on the decline in many parts of the world. Therefore, appropriate irrigation management plays a great role in the quality and quantity of these sources, and can help in realizing production potential and in obtaining high yields through reducing runoff losses and by delivering the required water to the root zone (Sepaskhah and Afshar-Chamanabad, 2002). Surface irrigation is used more than pressurized irrigation due to low cost and energy requirements. Innovative surface irrigation techniques are used for higher irrigation efficiency, among which alternate 
furrow irrigation decreases deep percolation, thereby increasing water use efficiency (Sepaskhah and Kamgar-Haghighi, 1997).

The major problem in surface irrigation is its low efficiency resulting from poor irrigation management (Khatri and Smith, 2006). The design, evaluation and simulation of surface irrigation systems dependent on a knowledge of infiltration properties of the soil and the movement of water over the field. Infiltration affects the advance, recession, runoff, and volume of infiltration during irrigation (Fonteh and Podmore, 1993). Spatial variation of infiltration rates makes the management of surface irrigation systems a very complex process (Rasoulzadeh and Sepaskhah, 2003). Infiltration is one of the most important parameters for designing surface irrigation systems, mainly for furrow irrigation (Walker and Skogerboe, 1987). It has a significant effect on water flow and solute transport in the soil surface and subsurface (Ebrahimian, 2014). Quantification of water infiltration into a soil is of great significance in the management of watersheds (Mukheibir, 2008). The performance of the mathematical models to simulate overland flow in fields within surface irrigation systems is dependent on the accuracy of estimation of infiltration parameters. Initial reduction in infiltration is related to the physical process of slaking to the development of an apedal, harvesting surface soil layer (Emdad et al., 2004). There are numerous methods for estimation of infiltration parameters in surface irrigation based on input data requirements, infiltration equations and solution methods (Bautista and Walker, 2010).

Gillies et al. (2007) reported that high irrigation efficiencies in surface irrigation were not out of reach if correct irrigation management was exercised and temporal and spatial changes in soil characteristics were considered. However, precise design for surface irrigation is required for higher irrigation efficiency and accurate prediction of the infiltration rate is of prime importance (Zerhun et al., 1996). There are two types of alternate furrow irrigation: 1) Alternate Furrow Irrigation (AFI) in which irrigated furrow (or non-irrigated furrow) is alternatively changed for every irrigation, and 2) Fixed Furrow Irrigation (FFI) in which irrigated furrow (or non-irrigated furrow) is fixed for every irrigation. This irrigation method has been known to improve water productivity in agricultural lands especially in arid and semi-arid regions (Ebrahimian et al., 2012). Application of alternate furrow irrigation would be expected to alleviate water shortages due to rapid population and decreasing per-capita water. Infiltration rate in alternate (every-other) furrows would be different from conventional furrows in the same field (Gillies and Smith, 2005).

Application of AFI can lead to increased lateral infiltration and decreased deep percolation, which will ultimately result in improved irrigation efficiency (Dialameh et al., 2017).

Slatni et al. (2011) also showed that the CFI treatment had the highest infiltration per unit area as compared to AFI and FFI. Alternate furrow irrigation succeeded in reducing infiltration in the experimental conditions, thus potentially reducing deep percolation losses. Field investigation and modeling on the infiltration process in alternate furrow irrigation would be helpful to reach the precise design of this kind of furrow irrigation system.

Many researchers used the Lewis-Kostiakov equation for infiltration in furrow irrigation and proposed methods for determination of its parameters (Scaloppi et al., 1995). Consequently, several equations have been proposed to describe furrow infiltration as a function of effectual factors on it. The commonly used equations are those proposed by Kostiakov and Kostiakov-Lewis (Nasseri and Neyshabori, 2006). 
Neshat and Parehkar (2007) showed in their research that the Lewis-Kostiakov model was the most suitable model for estimating cumulative infiltration and infiltration rate. Yongyong et al. (2012), determine the effectual infiltration variables, to evalute the performance of four classical infiltration models. The performance of four infiltration models (Philip model, Kostiakov-Lewis model, Kostiakov model, and Horton model) was investigated on the basis of evaluation indices. The Kostiakov-Lewis infiltration model with three parameters provided the best description of the relationship between cumulative infiltration and time.

The objective of this research was to determine the parameters of Lewis-Kostiakov infiltration equation in two types of alternate furrow irrigation (AFI and FFI) and conventional furrow irrigation in several irrigation events during sugar beet growing season. For this purpose, two-pointed method (Elliott and Walker, 1982) used to estimate the infiltration parameters of the Lewis-Kostiakov equation.

\section{Material and methods}

Field experiments of furrow irrigated sugar beet were conducted at the research field of the Kamalabad station of the Sugar Beet Research Institute in Karaj, Iran, at $50^{\circ} 55^{\prime} \mathrm{E}$ longitude, $35^{\circ} 55^{\prime} \mathrm{N}$ latitude and $1313 \mathrm{~m}$ altitude during 2013 and 2014 growing season of sugar beet. Climate in this region is semi-arid with total annual precipitation of $265 \mathrm{~mm}$. The soil in this area no salinity and drainage problems such as water table. Some physical properties of the experimental field soil are presented in Table 1, and some chemical irrigated water quality properties are shown in Table 2.

Table 1. Some physical properties of experimental field soil

\begin{tabular}{c|c|c|c|c|c|c|c}
\hline Depth cm & Clay \% & Silt \% & Sand \% & Texture & $\begin{array}{c}\text { Bulk density } \\
\text { gr/cm }^{3}\end{array}$ & $\begin{array}{c}\text { Field } \\
\text { capacity \% }\end{array}$ & $\begin{array}{c}\text { Permanent } \\
\text { wilting point \% }\end{array}$ \\
\hline $0-30$ & 31.4 & 42 & 26.6 & Clay loam & 1.47 & 27.4 & 14 \\
$30-60$ & 34.6 & 27.4 & 38 & Clay loam & 1.42 & 26.6 & 14.9 \\
\hline
\end{tabular}

Table 2. Chemical properties of irrigation water at the study area

\begin{tabular}{c|c|c|c|c|c|c|c|c|c}
\hline $\mathbf{H C O}_{\mathbf{3}}(\mathbf{m g} / \mathbf{l})$ & $\mathbf{C O}_{\mathbf{3}}(\mathbf{m g} / \mathbf{l})$ & $\mathbf{C l}(\mathbf{m g} / \mathbf{l})$ & $\mathbf{K}(\mathbf{m g} / \mathbf{l})$ & $\mathbf{N a}(\mathbf{m g} / \mathbf{l})$ & $\mathbf{M g}(\mathbf{m g} / \mathbf{l})$ & $\mathbf{C a}(\mathbf{m g} / \mathbf{l})$ & $\mathbf{E C}^{\mathbf{1}}(\mathbf{d S} / \mathbf{m})$ & $\mathbf{S A R}^{2}$ & $\mathbf{p H}$ \\
\hline 146 & 0 & 0.8 & 0.8 & 62 & 16 & 23 & 0.5 & 2.2 & 8 \\
\hline
\end{tabular}

${ }^{1}$ Electrical conductivity

${ }^{2}$ Specific absorption rate

The soil at the trial site up to $60 \mathrm{~cm}$ deep (effective depth for sugar beet root development), a uniform Clay loam soil texture with $\mathrm{EC}=0.58 \mathrm{dS} . \mathrm{m}^{-1}$, that does not limited growing plants. The soil has a high maintenance capacity that suitable for sugar beet cultivation.

Also water irrigation quality in term of salinity was suitable $\left(0.5 \mathrm{dS} . \mathrm{m}^{-1}\right)$ and not limited for sugar beet cultivation.

The experiments were conducted in the same field for the 2-year period. The experimental design was a randomized block with three replications. Each plot consists 
of 12 row of sugar beet that was $90 \mathrm{~m}$ long and $0.5 \mathrm{~m}$ wide, the slope of furrow was about $0.00019 \mathrm{~m} \cdot \mathrm{m}^{-1}$. Sowing density was 3-6 plants per meter.

The design consisted of three irrigation methods. The irrigation methods were alternate furrow irrigation (AFI), fixed furrow irrigation (FFI) and conventional furrow irrigation (CFI).

Outflow rate from the furrows was measured employing a Washington State College (WSC) flume (type II) that was put at the end of the furrow. The inflow rate was measured for each furrow using the volumetric method. The inflow-outflow hydrograph method was employed to calculate the final infiltration rate, which was obtained from the following equation (Eq. 1) when a constant outflow rate was reached (Fattah and Upadhyaya, 1996):

$$
f_{0}=\frac{Q_{\text {in }}-Q_{\text {out }}}{L}
$$

Where, $Q_{\text {in }}$ is the inflow rate in $\mathrm{m}^{3} / \mathrm{min}, \mathrm{Q}_{\text {out }}$ the outflow rate in $\mathrm{m}^{3} / \mathrm{min}$, L the length of the furrow in $\mathrm{m}$, and $\mathrm{f}_{0}$ base infiltration rate in $\mathrm{m}^{3} / \mathrm{m} / \mathrm{min}$. The volume of infiltrated water was calculated using the inflow and outflow volumes, and the Lewis-Kostiakov equation was employed to obtain the infiltration relation, which was as follows (Eq. 2):

$$
Z=k t^{a}+f_{0} t
$$

where, $\mathrm{Z}$ is the volume of infiltrated water per unit length of the furrow in $\mathrm{m}^{3} / \mathrm{m}, \mathrm{f}_{0}$ final infiltration rate into the soil in $\mathrm{m}^{3} / \mathrm{m} / \mathrm{min}$, $t$ time in minutes, and ' $a$ ', ' $k$ ' the empirical coefficients of the equation. The two-point method introduced by Elliott and Walker (1982) was employed to calculate the empirical parameters in the Lewis-Kostiakov equation of infiltration. For this purpose, furrows were marked with stakes at $10 \mathrm{~m}$ intervals, and the time water reached each station was recorded using a chronometer.

Walker (1989) used the empirical equation describing the advance curve in furrow irrigation to determine the infiltration parameters $(\mathrm{k}$; a) as follows $(E q .3)$ :

$$
x=p t^{r}
$$

where, $\mathrm{x}$ is the distance from the beginning of the furrow in $\mathrm{m}, \mathrm{t}$ time in minutes, and $\mathrm{r}$, $p$ coefficients of the equation can be evaluated from the two advance points and a simple logarithmic transformation of the power curve equation. The coefficients $a, k$, in the Lewis-Kostiakov equation can be calculated by using the water balance method in the furrow considering its two middle and end points. The coefficient "a" can be calculated from the following equation (Eq. 4):

$$
a=\frac{\ln \frac{V_{L}}{V_{0.5 L}}}{\ln \frac{t_{L}}{t_{0.5 L}}}
$$


Where $t_{L}$ and $t_{0.5 \mathrm{~L}}$ are the time water reaches the end and middle of the furrow, respectively, and $\mathrm{V}_{\mathrm{L}}$ and $\mathrm{V}_{0.5 \mathrm{~L}}$ are determined using the following equations (Eqs. 5 and б):

$$
\begin{gathered}
V_{L}=\frac{Q_{0} t_{L}}{L}-\delta_{y} A_{0}-\frac{f_{0} t_{L}}{1+r} \\
V_{0.5 L}=\frac{2 Q_{0} t_{0.5 L}}{L}-\delta_{y} A_{0}-\frac{f_{0} t_{0.5 L}}{1+r}
\end{gathered}
$$

where the inflow rate into the furrow is in $\mathrm{m}^{3} / \mathrm{min}, \mathrm{A}_{0}$ is the cross section of the inflow (which, in this study, was measured in the field), and $\delta_{\mathrm{y}}$ the flow shape factor was considered to be 0.8 . The coefficient "k" was determined using Equation 7:

$$
k=\frac{V_{L}}{\delta_{z} t_{L}^{a}}
$$

Where $\delta_{z}$ is the shape factor for infiltration into the furrow that is determined from the following equation (Eq. 8):

$$
\delta_{z}=\frac{a+r(1-a)+1}{(1+a)(1+r)}
$$

After the parameters in the equation of water infiltration into the furrows were determined, the volume of infiltrated water at various distances from the beginning of the furrow was calculated in irrigations. Infiltration opportunity at any time $T_{n}$ in minutes was determined using Equation 9:

$$
T_{n}=T_{r}-T_{a}
$$

Where, $T_{a}$ and $T_{r}$ are the water advancing and retreating time in the furrow, respectively, which were measured in the field in this research. The volumes of water infiltrated at specific points in the furrow were determined by putting the infiltration opportunities in the equation of infiltration into the furrow.

The amount of irrigation water, in the basis of soil moisture in depths of 0-30 and 30$60 \mathrm{~cm}$ was measured, and amount of water demand in each layer in the region of plant root relation was obtained by Equation 10.

$$
d n=\Sigma(\theta f c i-\theta i) \Delta z
$$

where $\mathrm{dn}$ is the net irrigation depth (m), $\theta$ fci and $\theta \mathrm{i}$ are the volumetric soil water contents in layer $i$ at field capacity and before irrigation, respectively $\left(\mathrm{m}^{3} / \mathrm{m}\right), \Delta z$ is the soil layer thickness $(\mathrm{m})$ and $\mathrm{n}$ is the number of soil layers. In the first year 13 irrigations were done and second year 11 irrigations were applied.

The objective of this research was to determine the parameters of Lewis-Kostiakov infiltration equation in AFI, FFI and CFI with irrigation events. Various models were 
fitted to the measured values and were studied the various management in order to determine the trend of changes in final infiltration with irrigation events.

\section{Results}

ANOVA of final infiltration rate is shown in Table 3. ANOVA was significant for irrigation events.

Table 3. ANOVA of final infiltration rate

\begin{tabular}{c|c|c|c|c|c|c}
\hline Year & Treatment & df & Sum of squares & MS & F-value & Sig. \\
\hline \multirow{3}{*}{2013} & CFI & 38 & $1.36 \times 10^{-8}$ & $9.77 \times 10^{-10}$ & 117.87 & $<0.0001^{* *}$ \\
& FFI & 38 & $1.64 \times 10^{-8}$ & $1.17 \times 10^{-9}$ & 89.04 & $<0.0001^{* *}$ \\
& AFI & 21 & $8.9 \times 10^{-9}$ & $6.2 \times 10^{-10}$ & 97.11 & $<0.0001^{* *}$ \\
\hline \multirow{3}{*}{2014} & CFI & 32 & $1.9 \times 10^{-8}$ & $1.59 \times 10^{-9}$ & 81.65 & $<0.0001^{* *}$ \\
& FFI & 32 & $2.1 \times 10^{-8}$ & $1.73 \times 10^{-9}$ & 277.3 & $<0.0001^{* *}$ \\
& AFI & 18 & $1.99 \times 10^{-8}$ & $1.64 \times 10^{-9}$ & 93.65 & $<0.0001^{* *}$ \\
\hline
\end{tabular}

Significant in $1 \%$ level

The effect of irrigation events on final infiltration rate significant, and the result of Duncan's multiple range test showed significant differences $(t<0.001)$ on three managements.

The amount of final infiltration rate in three irrigation managements is shown in Table 4.

Table 4. Total number of final infiltration rate

\begin{tabular}{|c|c|c|c|c|c|c|c|c|c|c|c|c|c|c|}
\hline \multirow{2}{*}{ Year } & \multirow{2}{*}{ Treatment } & \multicolumn{13}{|c|}{ Irrigation Event } \\
\hline & & 1 & 2 & 3 & 4 & 5 & 6 & 7 & 8 & 9 & 10 & 11 & 12 & 13 \\
\hline \multirow{3}{*}{2013} & CFI & $0.000161^{\mathrm{a}}$ & $0.000115^{\mathrm{b}}$ & $0.000109^{c}$ & $0.000106^{\mathrm{cd}}$ & $0.000102^{\mathrm{d}}$ & $0.000093^{\mathrm{et}}$ & $0.000093^{\mathrm{ef}}$ & $0.000092^{\mathrm{et}}$ & $0.000090^{\mathrm{et}}$ & $0.000092^{\mathrm{f}}$ & $0.000092^{\mathrm{t}}$ & $0.000091^{\mathrm{et}}$ & $0.000091^{\mathrm{f}}$ \\
\hline & FFI & $0.000168^{\mathrm{a}}$ & $0.000157^{b}$ & $0.000120^{c}$ & $0.000107^{\mathrm{d}}$ & $0.000106^{\mathrm{d}}$ & $0.000104^{\mathrm{d}}$ & $0.000108^{d}$ & $0.000105^{\mathrm{d}}$ & $0.000104^{\mathrm{d}}$ & $0.000107^{\mathrm{d}}$ & $0.000108^{8}$ & $0.000104^{\mathrm{d}}$ & $0.000106^{\mathrm{d}}$ \\
\hline & AFI & $0.000166^{\mathrm{a}}$ & - & $0.000135^{\mathrm{b}}$ & - & $0.000122^{\mathrm{c}}$ & - & $0.000116^{\mathrm{d}}$ & - & $0.000118^{\mathrm{e}}$ & - & $0.000111^{\mathrm{t}}$ & - & $0.000118^{\mathrm{e}}$ \\
\hline \multirow{3}{*}{2014} & CFI & $0.000166^{\mathrm{a}}$ & $0.000147^{b}$ & $0.000131^{\mathrm{c}}$ & $0.000108^{d}$ & $0.000103^{\mathrm{dc}}$ & $0.000095^{\mathrm{ef}}$ & $0.000097^{\mathrm{et}}$ & $0.000097^{\mathrm{ef}}$ & $0.000096^{\mathrm{et}}$ & $0.000092^{\mathrm{f}}$ & $0.000093^{t}$ & - & - \\
\hline & FFI & $0.000176^{\mathrm{a}}$ & $0.000175^{\mathrm{a}}$ & $0.000144^{b}$ & $0.000128^{c}$ & $0.000114^{\mathrm{d}}$ & $0.000112^{\mathrm{de}}$ & $0.000111^{\mathrm{de}} \mathrm{C}$ & $0.000110^{\mathrm{de}}$ & $0.000110^{\mathrm{de}}$ & $0.000110^{\mathrm{de}}$ & $0.000108^{\mathrm{e}}$ & - & - \\
\hline & AFI & $0.000161^{\mathrm{a}}$ & - & $0.000133^{b}$ & - & $0.000120^{c}$ & - & $0.000114^{\mathrm{d}}$ & - & $0.000110^{\mathrm{e}}$ & - & $0.000109^{\mathrm{e}}$ & - & - \\
\hline
\end{tabular}

Figure 1 shows trends of variation in final infiltration rate into the soil in the various irrigation management during the season with irrigation events in two years.

As shown in Table 4, the final infiltration rate decreased at end of the season in all management with logarithmic model. In first year, the final infiltration rate the start of the period $1.6^{*} 10^{-4}$ and decreased by 44,31 and $25 \%$ in CFI, FFI and AFI management and in second year, the final infiltration rate the start of the period $1.7 * 10^{-4}$ and decreased by 45, 37 and 36\% in CFI, FFI and AFI management. Finally, Table 4 shows that final infiltration rate was decreased by 44,34 and $30 \%$ in CFI, FFI and AFI management. Emdad et al. (2004) show that final infiltration rate was decreased $40 \%$ at the end of the season in clay loam soil texture. 


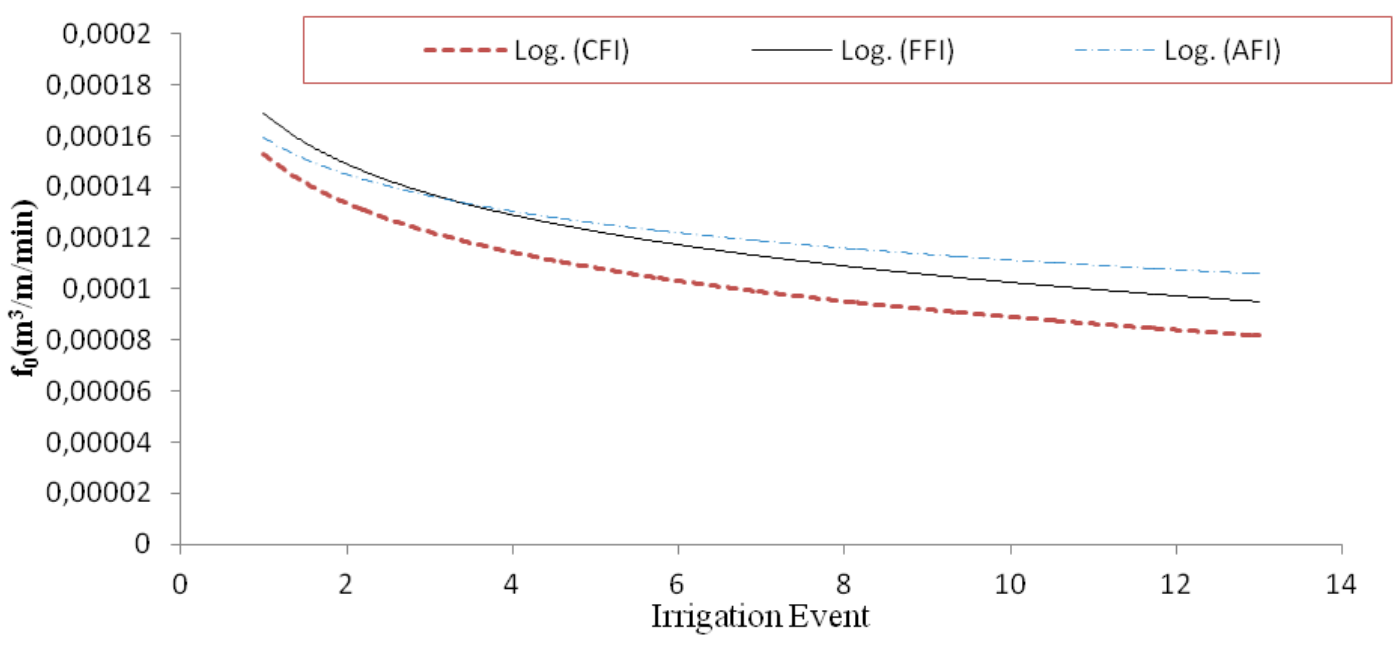

Figure 1. Final infiltration rate as a function of irrigation event (average of two years)

Various models were evaluated to determine the best regression fit between values of final infiltration rate and irrigation events. Models were evaluated by SAS software and their significant was investigated. The logarithmic model, presented below, was the best regression model with the highest correlation coefficient (Eqs. 11-13):

$$
\begin{aligned}
f_{0 C F I} & =-0.000028 \ln (\mathrm{IE})+0.000153 \\
R^{2} & =0.85 \\
f_{0 F F I} & =-0.000029 \ln (\mathrm{IE})+0.000169 \\
R^{2} & =0.79 \\
f_{0 A F I} & =-0.000021 \ln (\mathrm{IE})+0.000159 \\
R^{2} & =0.91
\end{aligned}
$$

Where $\mathrm{f}_{0 \mathrm{AFI}}$ is final infiltration rate in AFI management $\left(\mathrm{m}^{3} / \mathrm{m} / \mathrm{min}\right), \mathrm{f}_{0 \mathrm{FFI}}$ is final infiltration rate in FFI management $\left(\mathrm{m}^{3} / \mathrm{m} / \mathrm{min}\right), f_{0 C F I}$ is final infiltration rate in CFI management $\left(\mathrm{m}^{3} / \mathrm{m} / \mathrm{min}\right)$ and IE is irrigation event.

Regression analysis showed that there was a logarithmic relationship between final infiltration rate and irrigation event, which is a good function and significant (Fig. 1).

ANOVA of 'a' parameter in the Lewis-Kostiakov equation is shown in Table 5. ANOVA was significant for irrigation events. The effect of irrigation events on ' $a$ ' parameter in the Lewis-Kostiakov equation significant, and the result of Duncan's multiple range tests showed significant differences $(\mathrm{t}<0.001)$ on three managements.

ANOVA of ' $\mathrm{k}$ ' parameter in the Lewis-Kostiakov equation is shown in Table 6. ANOVA was significant for irrigation events. The effect of irrigation events on ' $\mathrm{k}$ ' parameter in the Lewis-Kostiakov equation significant, and the result of Duncan's multiple range test showed significant differences $(\mathrm{t}<0.001)$ on three managements.

Table 5. ANOVA of ' $a$ ' parameter in the Lewis-Kostiakov equation 


$$
-2610-
$$

\begin{tabular}{c|c|c|c|c|c|c}
\hline Year & Treatment & df & Sum of squares & MS $^{\mathbf{1}}$ & F-value & Sig. \\
\hline \multirow{3}{*}{2013} & CFI & 38 & 0.225 & 0.016 & 10.53 & $<0.0001^{* *}$ \\
& FFI & 38 & 0.324 & 0.023 & 9.44 & $<0.0001^{* *}$ \\
& AFI & 21 & 0.198 & 0.014 & 9.51 & $<0.0001^{* *}$ \\
\hline \multirow{3}{*}{2014} & CFI & 32 & 0.601 & 0.050 & 28.12 & $<0.0001^{* *}$ \\
& FFI & 32 & 0.592 & 0.049 & 8.84 & $<0.0001^{* *}$ \\
& AFI & 18 & 0.809 & 0.067 & 61.4 & $<0.0001^{* *}$ \\
\hline
\end{tabular}

${ }^{1}$ Mean square

${ }^{* *}$ Significant in $1 \%$ level

Table 6. ANOVA of ' $k$ ' parameter in the Lewis-Kostiakov equation

\begin{tabular}{c|c|c|c|c|c|c}
\hline Year & Treatment & df & Sum of squares & MS & F-value & Sig. \\
\hline \multirow{3}{*}{2013} & CFI & 38 & 0.00090 & 0.000070 & 12.87 & $<0.0001^{* *}$ \\
& FFI & 38 & 0.00089 & 0.000062 & 25.06 & $<0.0001^{* *}$ \\
& AFI & 21 & 0.00084 & 0.000095 & 23.50 & $<0.0001^{* *}$ \\
\hline \multirow{3}{*}{2014} & CFI & 32 & 0.00087 & 0.000072 & 16.87 & $<0.0001^{* *}$ \\
& FFI & 32 & 0.00087 & 0.000072 & 23.58 & $<0.0001^{* *}$ \\
& AFI & 18 & 0.00107 & 0.000090 & 21.75 & $<0.0001^{* *}$ \\
\hline
\end{tabular}

*** Significant in $1 \%$ level

Changes in infiltration parameters in the Lewis-Kostiakov equation were slight so that when the values of ' $a$ ', ' $k$ ' were studied in one growing season, it was observed that they declined very little. The related results are presented in Figures 2 and 3, and the obtained equations are as follows:

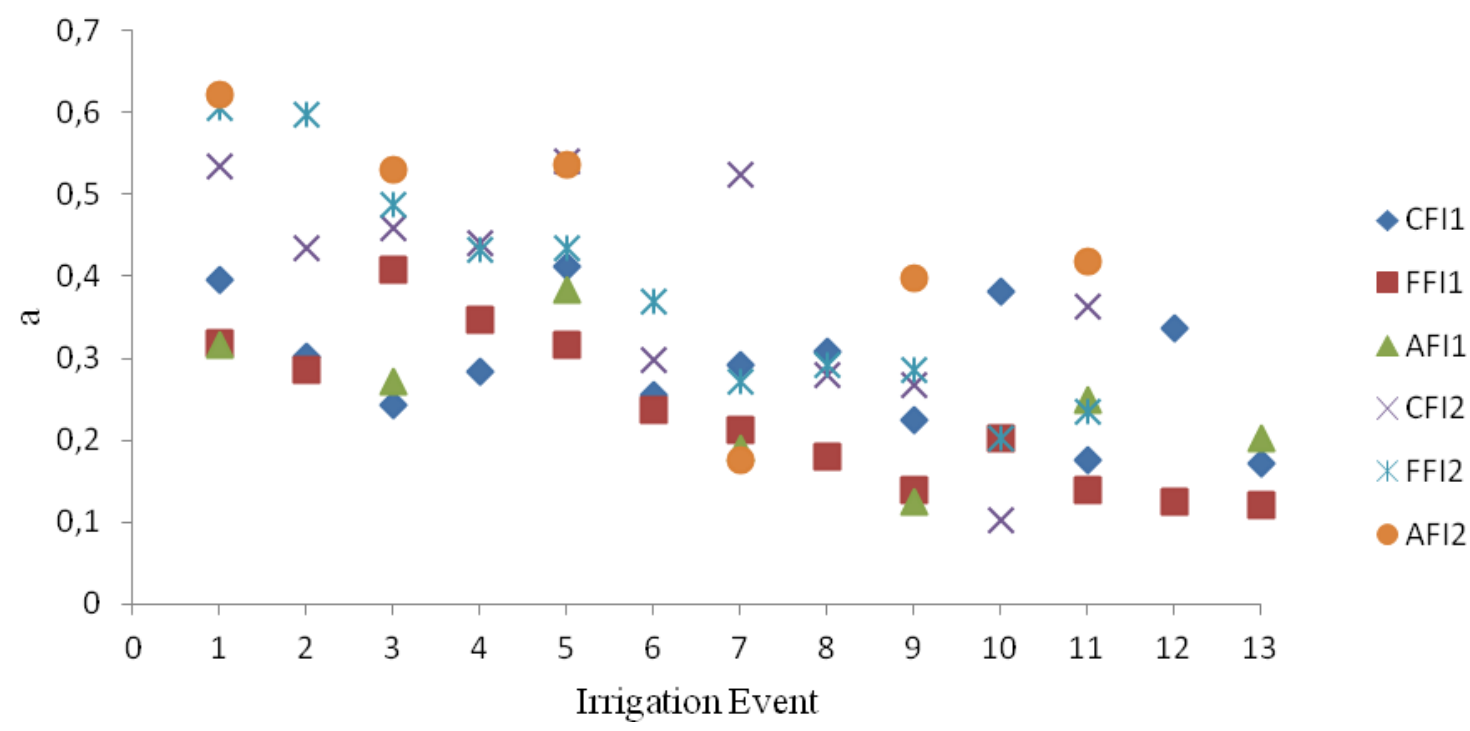

Figure 2. Lewis-Kostiakov parameters ' $a$ ' as a function of irrigation event 


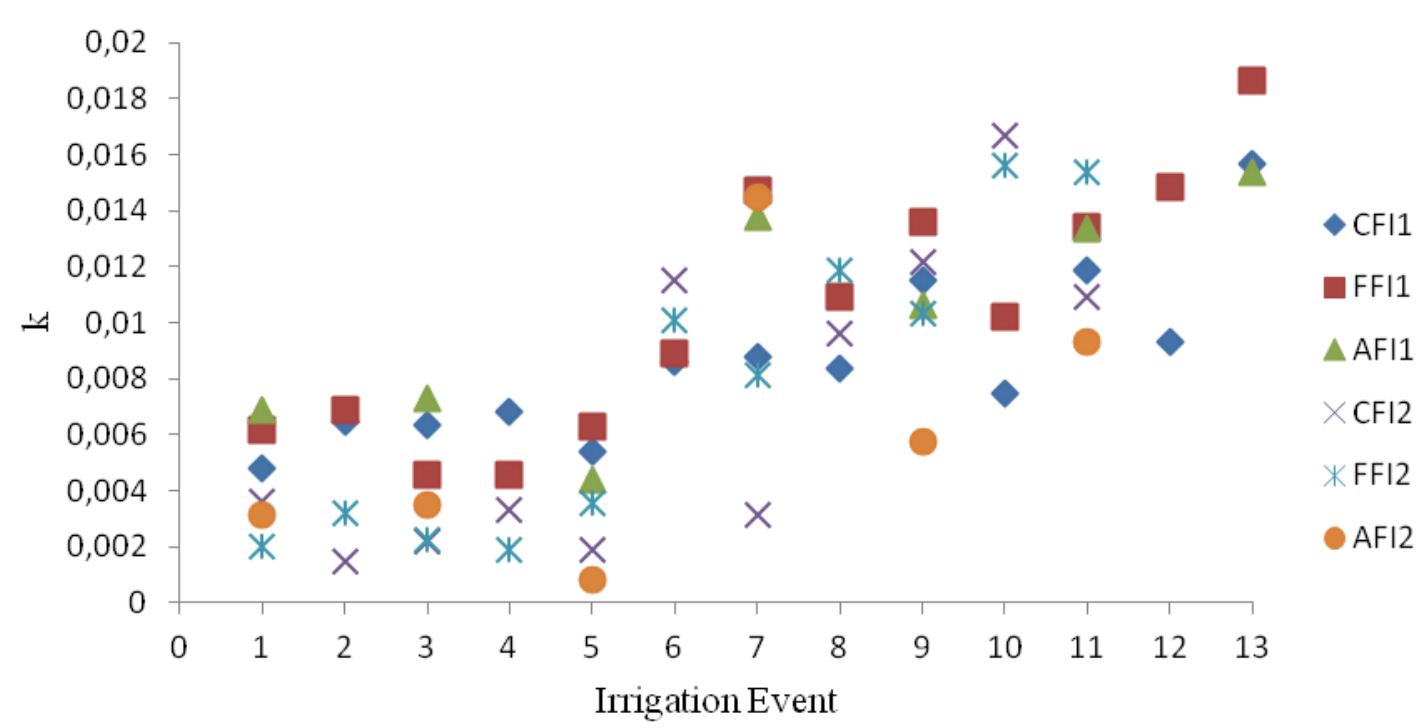

Figure 3. Lewis-Kostiakov parameters ' $k$ ' as a function of irrigation event

Amount of ' $a$ ' coefficient variations in Kostiakov-Lewis model, showed a decreasing trend during the growing season, but the ' $k$ ' coefficient had an incremental trend in CFI, FFI and AFI irrigation management system. The average value for ' $\mathrm{k}$ ' tended to decrease with time during the season for all treatments. Indicated that ' $\mathrm{k}$ ' and "a" were each significantly different between the early and late season period.

\section{Discussion}

The results of this study showed that at the beginning of the cultivating period, the final soil infiltration, due to increasing soil porosity by plowing increases too. Some soil physical properties, such as porosity, decrease due to the surface irrigation and low soil aggregate stability, which directly affects the hydraulic conductivity of saturated soil, in other words, it affects the final soil infiltration, therefore as a result, the final infiltration rate decreases (Slatni et al., 2011). Results show changes in final infiltration rate into the soil followed a descending trend. Soil compaction (subsidence) and destruction of the surface layer (disintegration of aggregates and surface crust formation) were the reasons for the decline in final infiltration rate during the period. Compaction and destruction of soil surface layer, together with decreased aggregate stability and crust formation, reduced final infiltration into the soil.

After the first irrigation, soil aggregate stability decreases due to the surface irrigation by formation of a crack on the surface of the soil. The simultaneous effect of these two factors causes a significant reduction in the final soil infiltration, therefore final soil infiltration according to Figure 1 is close to a constant limit. final soil infiltration was $1.6 \times 10^{-4} \mathrm{~m}^{3} / \mathrm{m} / \mathrm{min}$ at the beginning of the growing season in the first year and decreased in CFI, FFI and AFI management system by 44, 37 and $29 \%$ respectively, at the end of growing season. Similarly, in the second year, the final soil infiltration at the beginning of the season was $7.4 \times 10^{-4} \mathrm{~m}^{3} / \mathrm{m} / \mathrm{min}$, which was decreased, by 44,39 and $32 \%$, at the end of growing season, respectively. Parlange et al. (1982) showed that in furrow irrigation cropping system, the water infiltration rate during the 
first irrigation immediately following cultivation can often be markedly higher than later irrigation.

The AFI management showed the lowest infiltration losses, as compared to FFI and CFI. The infiltration rates in final irrigation were generally smaller in CFI than FFI and AFI. These results are in agreement with those by Sepaskhah and Afshar-Chamanabad (2002), who reported that the infiltration rate in the irrigated furrow of the FFI treatment was higher than in CFI furrows. As a consequence, the advance time would be higher in alternate furrows than in conventional furrows. Slatni et al. (2011), reported that the CFI treatment showed highest infiltration per unit area, compared to AFI and FFI. In this study, the infiltration per unit area was also higher for CFI than for both AFI and FFI management. However, infiltration per irrigated furrow was higher for AFI and FFI than for CFI, due to increased lateral water movement towards non-irrigated furrows.

In this research, indicated that ' $k$ ' and ' $a$ ' were significantly different between the early and late season period. Results of research conducted by Raine and Mcclymont (1997) and Zapata and Playan (2000) conform to those found in our research.

There was not a particular trend in the amount of coefficient changes during the crop growth period. In other words, the amount of ' $a$ ' was not predictable by the model, because of the existence of small seams in heavy soil texture which is an important factor in disturbing of time variation of ' $a$ ' coefficient during plant growth periods. According to the results of Hunsaker et al. (1993), Changes in 'a' coefficient have not shown conformity with logarithmic or linear model.

Although the ' $k$ ' coefficient is an experimental coefficient which is affected by the initial moisture (before irrigation) (Philip, 1957). Therefore, if in the various irrigation, the initial moisture content is approximately the same, the ' $\mathrm{k}$ ' coefficient is expected to remain almost constant. The results showed that ' $k$ ' coefficient correlates with the failure of specific trend or with the irrigation that has been carried out at different initial moisture levels.

Therefore ' $k$ ' and ' $a$ ' coefficients of Lewis-Kostiakov equation fixed in estimation equation and amount is $0.1-0.5$ for ' $a$ ' and 0.001-0.01 for ' $\mathrm{k}$ '.

Finally, cumulative infiltration decreased during plant growth season. Therefore to achieve proper management with considerable seasonal decrease of infiltration, time of irrigation must be increased.

AFI was successful in reducing infiltration in the experimental conditions, thus potentially reducing deep percolation losses. Also application efficiency increased in AFI management. Alternate furrow irrigation management in sugar beet may be feasible for water saving and reducing drainage. It can be concluded that using alternate furrow irrigation is a good water management technique to protect the environment by reducing runoff and increase water application efficiency (AE).

\section{Conclusions}

The results of this research showed that there were not specific trend changes in the values of the ' $k$ ' and ' $a$ ' coefficients in Lewis-Kostiakov penetration equation in different irrigation intervals during the growth periods. The initial penetration rate had a decreasing trend, which was predictable from logarithmic models.

Final infiltration rate decreased in CFI, FFI and AFI management system by 44, 38 and $30 \%$ respectively, at the end of growing season. High infiltration and steady infiltration rate in alternate furrows were found in this study. More horizontal water 
movement to non-irrigated furrows could establish this large difference between alternate and conventional furrow irrigation managements. Having different infiltration characteristics in alternate furrows, design variables of alternate furrow irrigation will be different from conventional furrow irrigation in the same field. This difference is even existed between AFI and FFI systems because of different infiltration characteristics. Therefore, the design and management of such irrigation methods should differ from conventional furrow irrigation. Field experiments indicated the AFI management could reduce large runoff losses in every irrigation events during sugar beet growing season.

Alternate furrow irrigation management in sugar beet may be feasible for water saving and reducing drainage. It can be concluded that using alternate furrow irrigation is a good water management technique to protect the environment by reducing runoff and increase water application efficiency (AE).

The current study has been done in clay loam texture soil and it might be different in other soil mixtures. Therefore, it is recommended that further experiments can be implemented in various soil textures and furrow lengths to evaluate infiltration parameters on irrigation managements.

Acknowledgments. The research was supported by the Sugar Beet Seed Institute.

\section{REFERENCES}

[1] Bautista, E., Walker, W. R. (2010): Advances in estimation of parameters for surface irrigation modeling and management. - National Decennial Irrigation Conference, Phoenix, Arizona, USA.

[2] Dialameh, B., Parsinejad, M., Ebrahimian, H., Mokhtari, A. (2017): Field comparison of infiltration in conventional and alternate furrow irrigation under various initial and boundary conditions. - Irrigation and Drainage 10: 403-413.

[3] Ebrahimian, H. (2014): Soil infiltration characteristics in alternate and conventional furrow irrigation using different estimation methods. - KSCE Journal of Civil Engineering 18(6): 1904-1911.

[4] Ebrahimian, H., Liaghat, A., Parsinejad, M., Playán, E. (2012): Distribution and loss of water and nitrate under alternate and conventional furrow fertigation. - Spanish Journal of Agricultural Research 10(3): 849-863.

[5] Elliott, R. L., Walker, W. R. (1982): Field evaluation of furrow infiltration and advance functions. - Transaction ASAE 25:396-400.

[6] Emdad, M. R., Smith, R. J., Fardad. H. (2004): Effect of water quality on soil structure and infiltration under furrow irrigation. - Irrigation Science 23(2): 55-60.

[7] Fattah, H., Upadhyaya, S. (1996): Effect of soil crust and soil compaction on infiltration in yolo loam soil. - Trans. ASAE 39: 79-84.

[8] Fonteh, M. F., Podmore, T. (1993): A physically based infiltration model for furrow irrigation. - Agricultural Water Management 23: 271-293.

[9] Gillies, M. H., Smith, R. J. (2005): Infiltration parameters from surface irrigation advance and run-off data. - Irrigation Science 24(1): 25-35.

[10] Gillies, M., Smith, R., Raine, R. (2007): Infiltration parameters from surface irrigation advance and run-off data. - Irrig. Sci. 24: 25-35.

[11] Hunsaker, D. J., Clemmens, J. Fangmeier, D. D. (1993): Cultural and irrigation management effects on infiltration, soil roughness and advance in furrow level basins. Trans. ASAE 42(6):1753-1762. 
[12] Khatri, L., Smith, R. (2006): Real- time prediction of soil infiltration characteristics for the management of furrow irrigation. - Irrig. Sci. 25: 33-43.

[13] Mukheibir, P. (2008): Water resources management strategies for adaptation to climate induced impacts in South Africa. - Water Resources Management 22: 1259-1276.

[14] Nasseri. A., Neyshabori, M. R. (2006): Estimation of Kostiakov infiltration parameters using initial soil moisture. - Journal of Agricultural Sciences Ankara University 12(3): 267-276.

[15] Neshat, A., Parehkar, M. (2007): The comparison of methods for determining the vertical infiltration rate. - J. Agric. Sci. Natur. Resour. 14(3): 186-195.

[16] Parlange, J. L., Lisle, I., Braddock, R. D. (1982): The three-parameter infiltration equation. - Soil Science 133(6): 337-341.

[17] Philip, J. R. (1957): The Theory of Infiltration, sorptivity and algebraic infiltration equations. - Soil Sci. 84: 257-264.

[18] Raine, R., Mcclymont, J. (1997): The development of guidelines for surface irrigation in areas with variable infiltration. - Proceeding of Australian Society of Sugarcane Technologists, pp. 293-301.

[19] Rasoulzadeh, A., Sepaskhah, A. R. (2003): Scale infiltration equation for furrow irrigation. - Bioseystems Enginiering 86(3): 375-383.

[20] Scaloppi, E. J., Merkley, G, P., Willardson, L. S. (1995): Intake parameters from advance and wetting phases of surface irrigation. - Journal of Irrigation and Drainage Engineering 121: 57-69.

[21] Sepaskhah, A. R. Afshar-Chamanabad, H. (2002): Determination of infiltration rate for every-other furrow irrigation. - Biosystems Engineering 82(4): 479-484.

[22] Sepaskhah, A. R., Kamgar-Haghighi, A. A. (1997): Water use and yield of sugarbeet grown under every-other furrow irrigation with different irrigation intervals. Agricultural Water Management 34: 71-80.

[23] Slatni, A., Zayani, K., Zairi, A., Yacoubi, S., Salvador, R., Playán, E. (2011): Assessing alternate furrow strategies for potato at the Cherfech irrigation district of Tunisia. Biosystems Engineering 108(2): 154-163.

[24] Walker, W. R. (1989): Guideline for Designing and Evaluating Surface Irrigation Systems. Irrigation and Drainage Paper 45. - FAO, Rome.

[25] Walker, W. R., Skogerboe, G. V. (1987): Surface Irrigation: Theory and Practice. Prentice-Hall, Inc., Englewood Cliffs, NJ.

[26] Yongyong, Z., Pute, W., Xining, Z., Ping, L. (2012): Evaluation and modeling of furrow infiltration for uncropped ridge-furrow tillage in loess plateau soil. - Soil Research 50: 360-370.

[27] Zapata, N., Playan, E. (2000): Elevation and infiltration in a level basin. - Irrigation Science 19(4): 155-164.

[28] Zerhun, D., Feyen, J., Reddy, J. M. (1996): Sensitivity analysis of furrow irrigation performance parameters. - Journal of Irrigation and Drainage Engineering 122: 49-57. 